\title{
Zinc and silver glass polyalkenoate cements: An evaluation of their antibacterial nature
}

\author{
A. Coughlan ${ }^{\mathrm{a}, \mathrm{b}}$, K. Scanlon ${ }^{\mathrm{c}}$, B.P. Mahon ${ }^{\mathrm{c}}$ and M.R. Towler ${ }^{\mathrm{a}, \mathrm{b}, *}$ \\ ${ }^{\text {a }}$ Inamori School of Engineering, Alfred University, Alfred, NY, USA \\ ${ }^{\mathrm{b}}$ Materials and Surface Science Institute, University of Limerick, National Technological Park, \\ Limerick, Ireland \\ ${ }^{\mathrm{c}}$ Institute of Immunology, National University of Ireland, Maynooth, Co. Kildare, Ireland
}

Received 24 August 2009

Accepted 4 March 2010

\begin{abstract}
A biofilm is an accumulation of micro-organisms and their extracellular products forming a structured community on a surface. Biofilm formation on medical devices has severe health consequences as bacteria growing in this lifestyle are tolerant to both host defence mechanisms and antibiotic therapies. However, silver and zinc ions inhibit the attachment and proliferation of immature biofilms. The objective of this study is to evaluate whether silver and zinc ions eluted from novel glass polyalkenoate cement (GPC) coatings have the ability to inhibit Methicillin-resistant Staphylococcus aureus (MRSA) in vivo. A silver and zinc-containing GPC coating was synthesised, deposited onto Ti6Al4V discs and placed in a specified amount of analytical water for 1, 7 and 30 days. The resulting elutes were collected and Atomic absorption spectroscopy was used to measure ion release. The elutes were injected into Galleria mellonella larvae infected with MRSA and the antibacterial properties of these elutes were evaluated in vivo. The majority of the zinc and silver ions were released within the first $24 \mathrm{~h}$; this corresponded with the greatest degree of protection observed in infected larvae. Results were compared to a conventional in vitro model where identical elutes were incubated with MRSA on nutrient agar. These results were consistent with those observed in the larval model, demonstrating a reduction in bacterial viability when co-cultured with elutes for $2 \mathrm{~h}$. This work confirms the promise of the Galleria mellonella as a model for the assessment of antimicrobial agents and demonstrates the capacity of novel silver and zinc-containing GPCs to retard the colonisation of MRSA.
\end{abstract}

Keywords: Glass polyalkenoate cement, antibacterial, zinc, silver

\section{Introduction}

Methicillin-resistant Staphylococcus aureus (MRSA) is the most commonly identified antibioticresistant pathogen in the developed world [1,2]. Although S. aureus was discovered in the 1950s, concerns were not raised until the 1980s with the identification of antibiotic resistant strains. With MRSA, mortality can be double that of a corresponding infection with an antibiotic-susceptible strain and morbidity far more extensive [1,2]. S. aureus persistently colonises at least one-third of mankind [3]. Once the human body's physical and immunological defences are compromised, $S$. aureus can cause infection. There are approximately 10,000 cases per year in the UK of blood stream infections (bacteraemia) with

\footnotetext{
${ }^{*}$ Address for correspondence: Dr. Mark Towler, Prof. Inamori School of Engineering, Alfred University, Alfred, NY 14802, USA. Tel./Fax.: +1 607871 2354; E-mail: Towler@alfred.edu.
} 
MRSA with a mortality rate of $40-50 \%$ and the incidence of $S$. aureus bacteraemia is 32 per 100,000 inhabitants in Ireland [2].

We have previously shown that silver and zinc-containing glass polyalkenoate cements (GPCs) eliminated $S$. aureus bacteria in vitro [4]. GPCs, formed by the reaction between an ion-leachable glass and an aqueous solution of polyacrylic acid (PAA) [5], have proven to be both antibacterial and cariostatic [5]; properties related to their ability to release beneficial amounts of therapeutic ions [6,7]. Commercially available GPCs are all based on aluminium glass chemistry [8]. However, the presence of aluminium retards the medical and surgical applications of such cements as aluminium ion $\left(\mathrm{Al}^{3+}\right)$ released in vivo can cause demineralisation of the bone [9] and has been implicated in the pathogenesis of degenerative brain diseases including Parkinson's and Alzheimer's disease [10,11]. The zinc ion $\left(\mathrm{Zn}^{2+}\right)$ performs a similar role in glass forming, to the $\mathrm{Al}^{3+}$ ion, in that it has the ability to act as an intermediate oxide, but it does not cause defective bone mineralisation [11,12].

$\mathrm{Zn}^{2+}$ is known to be antibacterial. Studies have shown that inhibition of bacterial growth correlates with released zinc from zinc phosphate cements (ZPC) [13] and zinc sulphate incorporated GPCs [14, 15]. The minimum zinc concentration required for bacterial inhibition of MRSA is $3 \times 10^{-2} \mathrm{ppm}$ [16]. Zinc inhibits multiple activities in the bacterial cell including glycolysis, transmembrane proton translocation and acid tolerance [17]. Silver is also a known antibacterial agent $[18,19]$ as the silver ion $\left(\mathrm{Ag}^{+}\right)$ binds to negatively charged components in proteins and nucleic acids, thereby causing structural changes in bacterial cell walls, membranes and nucleic acids that affect bacterial cell viability [20]. To have antimicrobial efficacy against MRSA, silver ions must be released in biocidal concentrations of at least 7.94 ppm [21].

The objective of this research is to determine the antibacterial efficacy of novel silver and zinccontaining GPCs against MRSA in a novel in vivo based study. The larvae of Galleria mellonella (G. mellonella) have been used as non-mammalian hosts to study the virulence of bacterial and fungal pathogens [22-25]. Similar to mammals, insects possess a circulatory system and comparable innate immune responses [26]. Analysis of insect responses to pathogens can provide an accurate indication of the innate mammalian response to that pathogen and a useful non-mammalian model for drug evaluation [23,27]. G. mellonella is an excellent model to work with as the species are of suitable weight $(250-400 \mathrm{mg}$ ) to allow for rapid delivery of pathogenic bacteria and thus examination of the inflammatory response to infection. There is also substantial correlation between the virulence of certain microbes in mice and in the G. mellonella model [26,28]. Although the use of higher animals such as mice and rats in most in vivo studies provide excellent results, the use of G. mellonella provides a screening method that is more cost-effective, less labour-intensive and more ethically acceptable.

\section{Materials and methods}

\subsection{Glass synthesis and characterisation}

One glass $\left(56.04 \mathrm{SiO}_{2}, 32.76 \mathrm{ZnO}, 0.33 \mathrm{Ag}_{2} \mathrm{O}\right.$ and $10.87 \mathrm{Na}_{2} \mathrm{O}$, mol. fraction), was synthesised by the melt quench route. Full details of the synthesis procedure have previously been reported by the authors [5] but are repeated for completeness. Appropriate amounts of analytical grade reagents were weighed out in a plastic tub and mixed in a ball mill $(1 \mathrm{~h})$, then dried in a vacuum oven $\left(100^{\circ} \mathrm{C}, 1 \mathrm{~h}\right)$. The reagents were fired in mullite crucibles $\left(1480^{\circ} \mathrm{C}, 1 \mathrm{~h}\right)$ and shock quenched into water. The resulting frit underwent grinding in a gyromill and the glass powder was passed through a $25 \mu \mathrm{m}$ sieve. All further work was undertaken on the sub $25 \mu \mathrm{m}$ particles. 
The GPC was prepared by mixing $0.5 \mathrm{~g}$ glass, with $0.2 \mathrm{~g}$ polyacrylic acid (PAA) and $0.25 \mathrm{ml}$ distilled water. Ciba specialty polymers (Bradford, UK) supplied the PAA (Mw, 210,000) in aqueous solution (25 vol\%). The PAA was subsequently freeze dried and ground (maximum particle size, $90 \mu \mathrm{m}$ ). Mixing was undertaken on a glass plate with a dental spatula in ambient laboratory conditions. The working time (the duration from commencement of mixing to the point when the cement is no longer pliable) and setting time [29] of the GPC was determined.

\subsection{Coating preparation}

Coatings were produced by spreading cement onto Ti6A14V discs (Engineering Sheets Limited, Limerick, Ireland) of known size ( $25 \mathrm{~mm} \emptyset, 2 \mathrm{~mm}$ ). Each construct was then clamped to another Ti6Al4V disc, separated from the coating by an acetate sheet. This sandwich structure was then stored in an oven $\left(37^{\circ} \mathrm{C}, 24 \mathrm{~h}\right)$, prior to declamping.

\subsection{Ion release}

Evaluation of both $\mathrm{Zn}^{2+}$ and $\mathrm{Ag}^{+}$ion release was undertaken at 1, 7 and 30 days by Atomic Absorption Spectroscopy (AAS). The constructs were matured in analytical water (Reagecon Limited, Shannon, Ireland); with up to $65 \mathrm{ml}$ of water immersing the samples. The amount of water was calculated using Eq. (1).

$$
\text { Rate of Solution }=\frac{S A}{10}+x ;
$$

SA - surface area; $x$ - a constant fixed number.

Full methodology has been reported previously [5], but will be repeated for completeness. Standard solutions of silver and zinc were formulated as per the literature [30]; zinc concentrations of $0.1,0.5,1.0$ and $2.0 \mathrm{ppm}$ and silver concentrations of $0.5,1.0,5.0$ and $10.0 \mathrm{ppm}$.

Ion release was evaluated using the Varian Spectra AA-220 FS Atomic Absorption Spectrometer (AAS, Varian, Australia) from each construct immersed in water $(n=3)$. Five $1 \mathrm{ml}$ extracts were taken from each sample. The zinc concentrations released from the coatings exceeded the detection limit of the apparatus and, for this reason, the solutions for evaluation of zinc release were diluted (1:10) with purified water. The $\mathrm{pH}$ of the solutions was also evaluated using an Accumet Portable $\mathrm{pH} / \mathrm{mV} /{ }^{\circ} \mathrm{C}$ Meter (Fisher Scientific, Ireland). Calibration was with pH4 and pH6 buffers.

\subsection{Preparation of the inoculum}

A $0.1 \mathrm{M}$ solution of potassium phosphate buffer (PPB) was made by preparing, separately, a $1 \mathrm{M}$ solution of dipotassium phosphate $\left(\mathrm{K}_{2} \mathrm{HPO}_{4}\right)$ and a $1 \mathrm{M}$ solution of potassium dihydrogen phosphate $\left(\mathrm{KH}_{2} \mathrm{PO}_{4}\right)$, then adding $71.7 \mathrm{ml}$ of $\mathrm{K}_{2} \mathrm{HPO}_{4}$ to $28.3 \mathrm{ml} \mathrm{KH}_{2} \mathrm{PO}_{4}$ to make $1 \mathrm{M}$ potassium phosphate buffer at $\mathrm{pH} 7.2$ and bringing the total volume to 11 (thereby diluting 1:10) with distilled water to make a $0.1 \mathrm{M}$ final solution.

Two dilutions of the elutes were undertaken. These were:

$-5 \%$ elute test. 
$50 \mu \mathrm{l}$ of elute was added to replicate bacterial cultures in a final volume of $1 \mathrm{ml}$ PPB. The culture had been grown to $\log$ phase and adjusted to a final conc. of $5 \times 10^{5} \mathrm{cfu} / \mathrm{ml}$.

- $10 \%$ elute test.

$100 \mu \mathrm{l}$ of elute was added to replicate bacterial cultures in a final volume of $1 \mathrm{ml}$ PPB. The culture had been grown to log phase and adjusted to a final conc. of $5 \times 10^{5} \mathrm{cfu} / \mathrm{ml}$.

Identical elute dilutions and bacterial concentrations were used in the subsequent in vitro antibacterial testing.

\subsection{Antibacterial testing}

Two antibacterial tests were performed; one in vitro and one in vivo.

\subsubsection{In vitro}

MRSA was incubated with or without the 5\% and $10 \%$ elutes in an orbital incubator for $2 \mathrm{~h}\left(37^{\circ} \mathrm{C}\right.$, $200 \mathrm{rpm}$ ). The concentration of viable bacteria was determined by colony counting; $100 \mu \mathrm{l}$ of serially diluted cultures were spread onto nutrient agar in triplicate and incubated at $37^{\circ} \mathrm{C}$ overnight. The number of bacterial colonies were counted using Quantity One Quantitation Software v4.4.1 (BioRad, CA, USA). Viability was determined as the percentage of a colony count compared to cultures of non-elute treated bacteria. Significance was determined by a paired $t$-test analysis.

\subsubsection{In vivo}

A non-mammalian model previously used to assess antibiotic efficacy was adapted for use in this study [28]. G. mellonella in final larval stage were stored in the dark before being infected with $1 \times 10^{6}$ CFU/larvae of MRSA. Delivery was by microinjection into the last proleg. After $20 \mathrm{~m}$ recovery, a second injection of either $20 \mu \mathrm{l} 1 \mathrm{mM}$ PPB or $20 \mu \mathrm{l}$ scaffold elute was administered. The larvae were then held in a $30^{\circ} \mathrm{C}$ incubator and assessed for viability at 48 and $72 \mathrm{~h}$. Six G. mellonella were used per treatment. G. mellonella that received no bacteria remained $100 \%$ viable. Larvae were assessed for responsiveness (movement) and colour (yellow or black), where discolouration is indicative of innate immune activation and melanisation (Fig. 1).

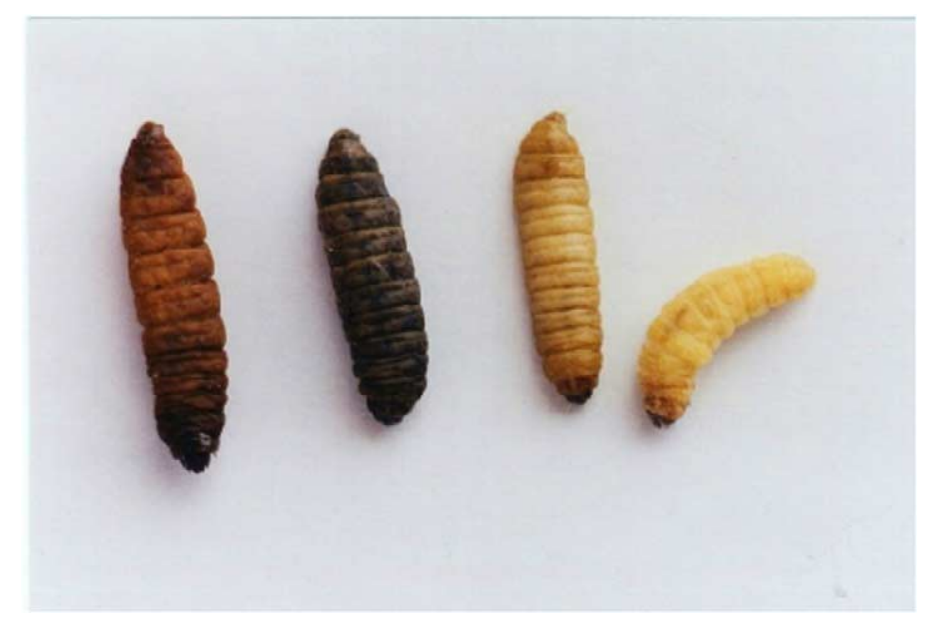

Fig. 1. G. Mellonella: Dead larvae are black and living larvae are yellow. 


\section{Results and discussion}

\subsection{Glass synthesis and characterisation}

The glass was produced and characterised as outlined in the methods section.

\subsection{Cement characterisation}

The cement was formulated by mixing the glass powders with the PAA and water at the ratio stated in Section 2.2. Working and setting times are shown in Table 1.

The cements have long setting times which helps to ensure high levels of ion release.

\subsection{Ion release evaluation}

The cumulative levels of $\mathrm{Zn}^{2+}$ and $\mathrm{Ag}^{+}$released were evaluated using AAS. This data has already been documented [5] but is repeated in Fig. 2, for completeness. A pH of 7 was recorded for all solutions at all time frames. It is evident that the majority of both $\mathrm{Zn}^{2+}(1.5 \mathrm{ppm})$ and $\mathrm{Ag}^{+}(0.2 \mathrm{ppm})$ release occurs in the first $24 \mathrm{~h}$, but there is a continual release (Fig. 2) throughout the evaluation period (30 days), with another $1 \mathrm{ppm} \mathrm{Zn}^{2+}$ being released after 7 days and the remaining $1 \mathrm{ppm}$ being released over 30 days. Over the next 29 days, only an additional $0.1 \mathrm{ppm} \mathrm{Ag}^{+}$was released by the coatings.

\subsection{Antibacterial evaluation}

\subsubsection{In vitro test}

The results of the colony counts are displayed schematically in Fig. 3.

Table 1

Working and setting times of the cement formulation

\begin{tabular}{ccc}
\hline Cement & Wt & St \\
\hline $\mathbf{A}$ & $5 \mathrm{~m} \mathrm{22} \mathrm{s}$ & $16 \mathrm{~h} 15 \mathrm{~m} \mathrm{23 \textrm {s }}$ \\
\hline
\end{tabular}

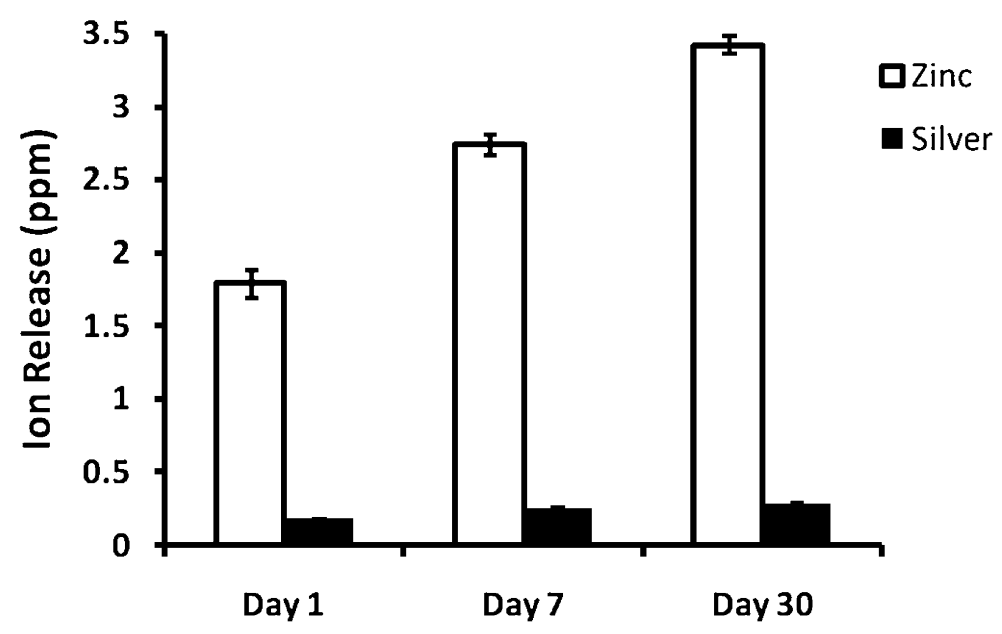

Fig. 2. Cumulative ion release profiles for zinc and silver from the GPC. 


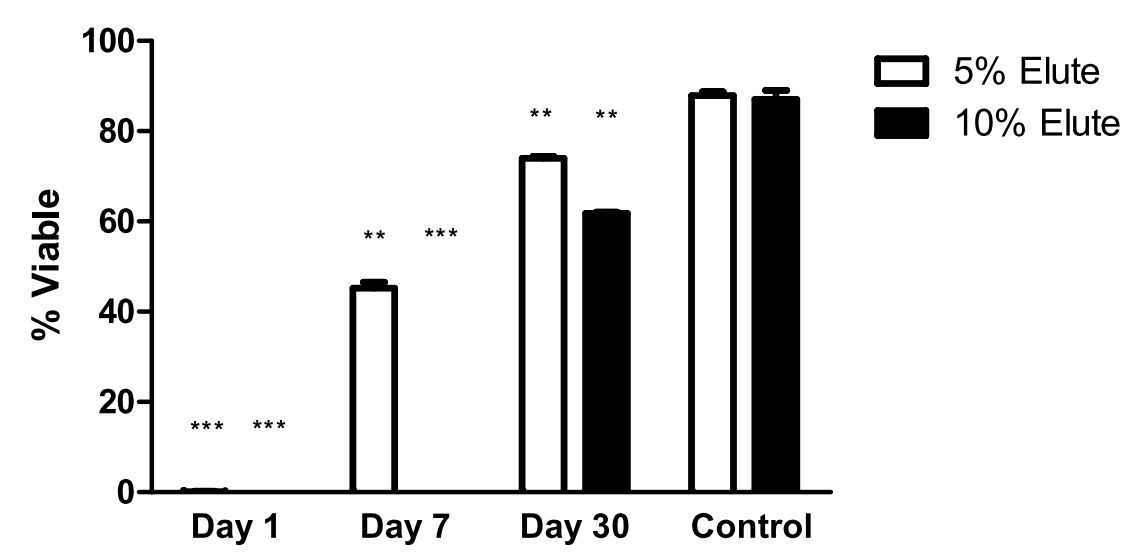

Fig. 3. 1, 7 and 30 day and Control (water) of the 5\% and $10 \%$ colonies Each point represents the mean \pm SE of triplicate results, significance was determined by paired $t$-test compared with water control, $* * * p<0.005, * * p<0.05$.
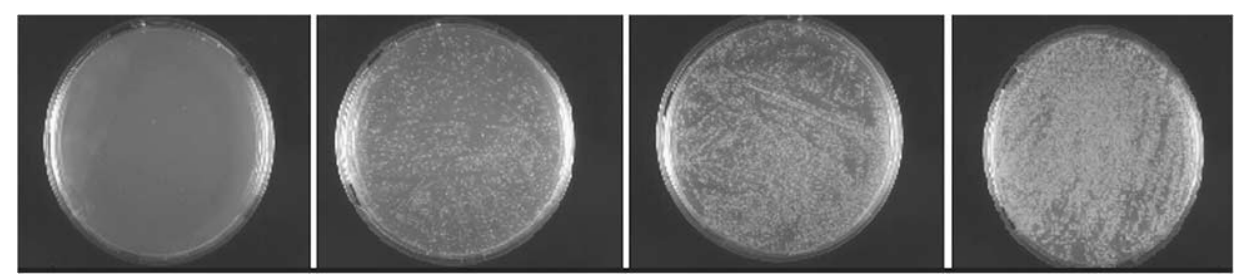

Fig. 4. 1, 7 and 30 day and control images of the $5 \%$ colony count.
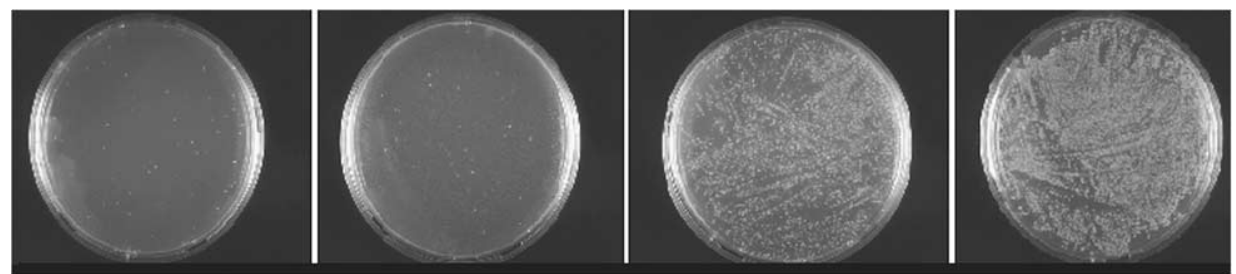

Fig. 5. 1, 7 and 30 day and control images of the $10 \%$ colony count.

A significant reduction in bacterial viability was observed for both the $5 \%$ and $10 \%$ dilutions of day 1 , 7 and 30 elutes when compared with controls (Figs 4 and 5). Day 30 elutes showed a reduced but efficacious antibacterial function. As expected, these results corresponded with the levels of $\mathrm{Zn}^{2+}$ and $\mathrm{Ag}^{+}$ measured in the GPC solutions, demonstrating greater microbicidal function at higher concentrations. These results indicate that the levels of $\mathrm{Zn}^{2+}$ and $\mathrm{Ag}^{+}$released from the GPC are at concentrations high enough to reduce the viability of MRSA and that while the levels of each reduces over time, the elutes remain effective up to 30 days. With reference to the literature, $\mathrm{Zn}^{2+}$ release from these coatings was measured in biocidal concentrations for MRSA $\left(>3 \times 10^{-2} \mathrm{ppm}\right)$ [17], but below toxic levels for humans [31]. However, the concentration of $\mathrm{Ag}^{+}$released were both below biocidal concentrations for MRSA (7.94 ppm) [21] and toxic levels for humans [21]. This antibacterial efficacy is independent of $\mathrm{pH}$, given that a $\mathrm{pH}$ of 7 was recorded for all solutions at all time frames, inferring that the metal ion release, and not $\mathrm{H}^{+}$release from the polyacrylic acid, is responsible for the coatings' antibacterial efficacy. From this, it can be assumed that the $\mathrm{Zn}^{2+}$ release, not the $\mathrm{Ag}^{+}$or $\mathrm{pH}$ effects, cause antibacterial 


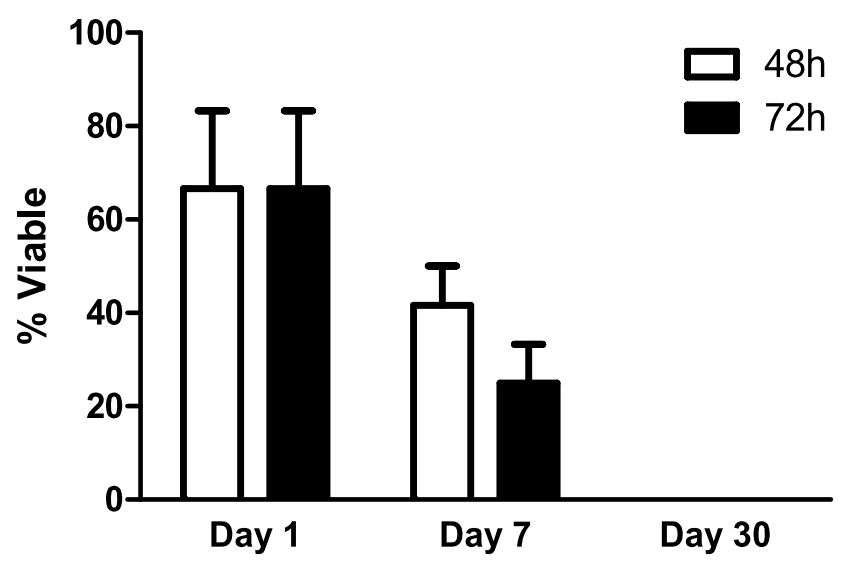

Fig. 6. 1, 7 and 30 day elutes $\%$ survival at 48 and $72 \mathrm{~h}$. Each point represents the mean \pm SE.

efficacy. However, further tests need to be performed on comparable coatings with no silver content to confirm this finding.

\subsubsection{In vivo test}

The viability of G. mellonella larvae were assessed at 48 and $72 \mathrm{~h}$, post treatment (Fig. 6). Larvae were infected with $S$. aureus MRSA followed by cement elutes from 1, 7 and 30 days, or control $1 \mathrm{mM}$ PPB. Larvae that were not infected remained $100 \%$ viable both in terms of movement and colouration. G. Mellonella that received the control $1 \mathrm{mM}$ PPB post infection were all non-viable (immobile and discoloured) at $48 \mathrm{~h}$. Viability was rescued with the addition of GPC elutes from 1 and 7 days up to $72 \mathrm{~h}$ post infection. Larval survival was maintained with day 1 elutes but demonstrated reduced efficacy over time in the G. Mellonella that received 7 day elutes. GPC elutes from 30 day demonstrated no beneficial effects when administered, resulting in $100 \%$ mortality at $48 \mathrm{~h}$. Confirming the results observed in vitro, antimicrobial function by GPC elutes in an in vivo larval model correlated with the concentration of zinc and silver ions. Elutes that contained the highest ion levels exhibited the greatest capacity to inhibit bacterial colonisation.

\section{Conclusion}

Biofilm formation on medical devices has severe health consequences as it provides a sanctuary for bacteria which are tolerant to both host defence mechanisms and antibiotic therapies. However, $\mathrm{Zn}^{2+}$ and $\mathrm{Ag}^{+}$are known to inhibit the attachment and proliferation of immature biofilms. The objective of this work was to determine, using a novel in vivo test modality and an accepted in vitro test modality as control, the ability of zinc and silver ion release, from novel GPCs, to inhibit or retard the colonisation of MRSA. It is evident that the majority of both $\mathrm{Zn}^{2+}$ and $\mathrm{Ag}^{+}$release occurs in the first $24 \mathrm{~h}$, but there is a continual release (Fig. 2) throughout the evaluation period (30 days). A serendipitous effect of this work is that G. mellonella may be suitable as a pre screening tool to determine the antibacterial efficacy of solutions, minimising the need for small animal testing in the future.

\section{References}

[1] I. Gould, MRSA in Practice, Royal Society of Medicine Press, London, UK, 2006. 
[2] H. Grundmann, M. Aires-de-Sousa, J. Boyce and E. Tiemersma, Emergence and resurgence of meticillin-resistant Staphylococcus aureus as a public-health threat, Lancet 368 (2006), 874-885.

[3] S.M.M. Cavalcanti, E.R.D. França, C. Cabral, M.A. Vilela, F. Montenegro, D. Menezes and Â.C.R. Medeiros, Prevalence of Staphylococcus aureus introduced into intensive care units of a University Hospital, Braz. J. Infect. Dis. 9 (2005), $56-63$.

[4] A. Coughlan, D. Boyd, C.W.I. Douglas and M.R. Towler, Antibacterial coatings for medical devices based on glass polyalkenoate cement chemistry, J. Mater. Sci. Mater. Med. 19 (2008), 3555-3560.

[5] J.A. Platt, Resin cements: into the 21st century, Compend. Contin. Educ. Dent. 20 (1999), 1173-1176, 1178, $1180-1172$.

[6] H. Forss, Release of fluoride and other elements from light-cured glass ionomers in neutral and acidic conditions, J. Dental Res. 72 (1993), 1257-1262.

[7] S.B. Mitra, Photocurable cements based on polyalkenoates ion-leachable glass hybrid systems, Abstr. Pap. Am. Chem. Soc. 113 (1991), 202-262.

[8] J.W. Nicholson, Chemistry of glass-ionomer cements: a review, Biomaterials 19 (1998), 485-494.

[9] M.C. Blades, D.P. Moore, P.A. Revell and R. Hill, In vivo skeletal response and biomechanical assessment of two novel polyalkenoate cements following femoral implantation in the female New Zealand White rabbit, J. Mater. Sci. Mater. Med. 9 (1998), 701-706.

[10] C. Exley, A molecular mechanism of aluminum-induced Alzheimer's disease?, J. Inorg. Biochem. 76 (1999), $133-140$.

[11] P. Zatta, T. Kiss, M. Suwalsky and G. Berthon, Aluminium(III) as a promoter of cellular oxidation, Coord. Chem. Rev. 228 (2002), 271-284.

[12] L.D. Quarles, G. Murphy, J.B. Vogler and M.K. Drezner, Aluminum-induced neo-osteogenesis: a generalized process affecting trabecular networking in the axial skeleton, J. Bone Miner. Res. 5 (1990), 625-635.

[13] D. Boyd, H. Li, D.A. Tanner, M.R. Towler and J.G. Wall, Antibacterial effects of zinc ion migration from zinc-based glass polyalkenoate cements, J. Mater. Sci. Mater. Med. 17 (2006), 489-494.

[14] J. Foley and A. Blackwellb, Ion release from copper phosphate cement and influence on streptococcus mutans growth in vitro: a comparative study, Caries Res. 37 (2003), 416-424.

[15] P.W.R. Osinaga, R.H.M. Grande, R.Y. Ballester, M.R.L. Simionato, C.R.M. Delgado-Rodrigues and A. Muench, Zinc sulfate addition to glass-ionomer-based cements: influence on physical and antibacterial properties, zinc and fluoride release, Dental Mater. 19 (2003), 212-217.

[16] P.G. Sohnle and B.L. Hahn, Effect of zinc-reversible growth-inhibitory activity in human empyema fluid on antibiotic microbicidal activity, Antimicrob. Agents Chemother. 44 (2000), 139-142.

[17] L.A. Sampath, N. Chowdhury, L. Caraos and S.M. Modak, Infection resistance of surface modified cathers with either short lived or prolonged activity, J. Hosp. Infect. 30 (1995), 201-210.

[18] G. Cook, J.W. Costerton and R.O. Darouiche, Direct confocal microscopy studies of the bacterial colonisation in vitro of a silver coated heart valve sewing cuff, Int. J. Antimicrob. Agents 13 (2000), 169-173.

[19] W. Ghandour, J.A. Hubbard, J. Deistung, M.N. Hughes and R.K. Poole, The uptake of silver ions by Escherichia coli K12: toxic effects and interaction with copper ions, Appl. Microbiol. Biotechnol. 28 (1988), 559-565.

[20] H.V.R. Dias, K.H. Batdorf, M. Fianchini, H.V.K. Diyabalanage, S. Carnahan, R. Mulcahy, A. Rabiee, K. Nelson and L.G. van Waasbergen, Antimicrobial properties of highly fluorinated silver(I) tris(pyrazolyl)borates, J. Inorg. Biochem. 100 (2006), 158-160.

[21] G. Cotter, S. Doyle and K. Kavanagh, Development of an insect model for the in vivo pathogenicity testing of yeasts, FEMS Immunol. Med. Microbiol. 27 (2000), 163-169.

[22] K. Kavanagh and E.P. Reeves, Exploiting the potential of insects for in vivo pathogenicity testing of microbial pathogens, FEMS Microbiol. Rev. 28 (2004), 101-112.

[23] B.B. Fuchs and E. Mylonakis, Using non-mammalian hosts to study fungal virulence and host defense, Curr. Opin. Microbiol. 9 (2006), 346-351.

[24] L.R. Scully and M.J. Bidochka, Developing insect models for the study of current and emerging human pathogens, FEMS Microbiol. 263 (2006), 1-9.

[25] G. Jander, L.G. Rahme and F.M. Ausubel, Positive correlation between virulence of Pseudomonas aeruginosa mutants in mice and insects, J. Bacteriol. Vol. 182 (2000), 3843-3845.

[26] J.A. Hoffmann, Innate immunity of insects, Curr. Opin. Immunol. 4 (1995), 4-10.

[27] M. Brennan, D.Y. Thomas, M. Whiteway and K. Kavanagh, Correlation between virulence of Candida albicans mutants in mice and Galleria mellonella larvae, FEMS Immunol. Med. Microbiol. 34 (2002), 153-157.

[28] ISO:9917:1991, Dental Water Based Cements, Geneve, Switzerland, 1991.

[29] C. Burgess, Valid Analytical Methods and Procedures Handbook, Royal Society of Chemistry, Cambridge, UK, 2000.

[30] ASTDR, Toxicological Profile for Zinc, Agency for Toxic Substances and Disease Registry, Atlanta, GA, 2005.

[31] R.A. Faust, Toxicology Summary for Silver, U.S. Department of Energy, Oak Ridge, TN, 1992. 
Copyright of Bio-Medical Materials \& Engineering is the property of IOS Press and its content may not be copied or emailed to multiple sites or posted to a listserv without the copyright holder's express written permission. However, users may print, download, or email articles for individual use. 